REVISTA ECONOMÍA

Vol. 70, N. ${ }^{\circ}$ III (mayo 20I8), 209-22I

\title{
INDIVIDUACIÓN Y COHESIÓN SOCIAL: ENTRE LA LÓGICA ECONÓMICA Y LA RACIONALIDAD MORAL
}

\author{
JORGE GRANDA AGUILAR \\ Universidad Central del Ecuador \\ Recepción de manuscrito: 2 de febrero de 2018 \\ Aceptación versión final: 13 abril de 2018
}

\begin{abstract}
RESUMEN En el debate contemporáneo sobre la naturaleza de lo distribucional, la elección entre «crecimiento económico» $\mathrm{y}$ "protección social» resulta fundamental. Aunque las teorías modernas más influyentes debaten esta disyuntiva como parte de la bipoliaridad «libertad-justicia», sus implicaciones devienen cruciales en el seno de la más reciente deliberación teórica, especialmente, luego del estallido de la burbuja inmobiliaria. No solo se actualizan los desarraigos característicos a los mercados, sino que en medio de la crisis eclipsan tanto sus competencias omnicomprensivas como las lógicas electivas de naturaleza cerrada que las caracterizan. Este trabajo pretende detectar las implicaciones distibucionales subyacentes en un contexto electivo más abierto.
\end{abstract}

PALABRAS CLAVE Individuación, cohesión social, elección, racionalidad.

ABSTRACT In the contemporary debate about the nature of the distributional, the choice between 'economic growth' and 'social protection' is fundamental. Although the most influential modern theories debate this dilemma as part of the bipoliarity 'freedom-justice', its implications become crucial in the most recent theoretical deliberation, especially after the bursting of the housing bubble. Not only the characteristic uproots to the markets are updated, but in the midst of the crisis they eclipse both their omnicomprehensive competences and their elective logics of a closed nature that characterize them. This paper aims to detect the underlying distibutional implications in a more open elective context.

KEYWORDS Individuation, social cohesion, choice, rationality.

JEL CODES B59, I3, J46.

\section{INTRODUCCIÓN}

Con el término «protección social», recurrentemente se invoca acciones de política destinadas a reparar ciertas situaciones de desventaja e indefensión que afectan a determinadas capas de la sociedad sujetas a patrones más o menos intensos y sistémicos de exclusión, la mayoría de veces, originadas en la desigualdad económica y social existentes. Claramente, tras esta formalidad expositiva, el discurso toma distancia del razonamiento económico predominante, 
particularmente de aquél que funda la socialidad a partir de la praxis del agente maximizador y se muestra mucho más hermanado con el punto de vista que postula que la economía forma parte de una malla de relaciones «supraindividuales».

En efecto, las formas de comportamiento que buscan maximizar las utilidades individuales como mecanismo electivo per se del bienestar, no resultan adecuadas para la comprensión del proceso decisional si se soslayan ciertas condiciones según las cuales la falta de oportunidades sociales menoscaban la finalidad intrínseca del bienestar esperado, dado que en esas condiciones la regla de elección individual opera, sin excepción, en un campo de juego desnivelado, cuyas asimetrías se le imponen exógenamente y, como consecuencia, se erosionan los soportes que sustentan la autonomía y libertad individual.

Al priorizarse, en principio, un prisma que centra toda su atención en lo instrumental, el tópico electivo en ciernes y sus efectos subyacentes se posan inequívocamente frente al fenómeno de la desigualdad, en realidad, de cara a la inequidad, ese tipo de desigualdad más blanda y, por tanto, operativamente evitable. Un mejoramiento del desempeño de lo distribucional, en consecuencia, resultaría crucial para mitigar esas asimetrías. Su legitimidad, sin embargo, no atañe tanto al mundo económico, sino al de la moral que en la modernidad se construye como suplemento del primero, donde al intercambio de «bienes no morales» —intercambio de bienes privados - que exacerban la desigualdad, debe seguirle el intercambio de bienes morales —igualdad, solidaridad, progresividad-como condición sine qua non de la «cohesión social».

Medida por esa métrica más moral, la cohesión social resulta asediada con relativa frecuencia, empero, por el estallido de fenómenos como los de desempleo y de paro en las sociedades avanzadas, y por precariedad laboral e informalidad en las economías periféricas. Originados en una mezcla combinada de recesiones profundas y trampas de desarrollo, esta falta de estabilidad del sistema desnuda, en ambos contextos, la ausencia de contenido económico de la cohesión social. En los dos casos, y en el uno más que en el otro, los fuertes desarraigos laborales, sociales, identitarios, ambientales, surgen como resultado inintencional de la extensión compulsiva del intercambio de bienes no morales, ahora, a una escala global.

Esta última prescripción, en realidad, se atiene más al criterio de las consecuencias que siguen al comportamiento maximizador. La falta de mecanismos protectores para hacer frente a los desarraigos sociales de todo tipo, transvasa el ámbito estricto de la elección individual hacia uno más vasto, el de la relación social, el del lazo social. Dos aproximaciones destacan el itinerario seguido para el discernimiento convincente de esta suerte de vaciamiento social propio del capitalismo y de la sociedad industrial, pioneramente advertido por Weber y Durkheim ya bien entrado el siglo xIX cuando se disipan las promesas de una gran salida salvadora que mengüe las «patologías» generadas por la modernidad (Bernstein, 1994).

Una de ellas, más clásica, propuesta por Karl Polanyi, que funda el fenómeno asociándolo a la desposesión y a la mercantilización del trabajo y de la naturaleza como sus rasgos esenciales a partir de los cuales la sociedad de mercado se «inhabilita» para la protección social y del hábitat. ${ }^{1}$ La otra, más contemporánea a tono con el pensamiento de Amartya Sen y Thomas Piketty; el primero, subraya la necesidad de reconstruir la exigencia de la vida en sociedad y para lo cual lo fundamental no solo es el mecanismo electivo, sino el rol de ciertas instituciones sociales niveladoras (Sen, 1999); el segundo, por su parte, documenta los efectos 
potencialmente catastróficos de la expansión de la desigualdad y el agrietamiento subsecuente de la cohesión social.

Este estudio enfatiza, sumariamente, las dimensiones detrás de éste, con seguridad el fenómeno más saliente e irresuelto por la Era Moderna según el cual la disputa por lo distribucional que en ella se posa sobre la bipolaridad «libertad» $\mathrm{y}$ «justicia» adquiere un matiz más de tipo instrumental y en sintonía con su métrica de carácter autorreferencial a partir de la que la lógica económica — el intercambio de bienes privados - se legitima a sí mismo con el resultado de una elección cerrada en la que cada uno de los polos de esa escala binaria operan como «sustitutos»; en contraste, con elecciones más abiertas que les confieren, en cambio, roles menos asimétricos. Simplificando, libertad y justicia definen el territorio y la demarcación entre axiológicas alternativas cuyos contenidos afectan los mecanismos modernos para la instrumentación de la redistribución.

En efecto, tanto el «marxismo de elección racional» como el keynesianismo contemporáneo, por ejemplo, atan la desigualdad a las emergentes distorsiones del mercado que redireccionan los incentivos no en el sentido de crear nueva riqueza, sino de arrebatársela a los demás, lo cual, y en cierto modo, legitima el retorno del término explotación defendido por C. Marx, acotándolo, sin embargo, a un campo manifiesto de connotación distribucional tipo suma cero. El bienestar de la clase social privilegiada es fruto de la severa penuria de la clase desposeída.

En estricto rigor, y aun cuando la mitigación de los desarraigos contemporáneos corre a cargo de los Estados de bienestar y sus sistemas de protección social en cuyo seno se desarrollan acciones de amparo contra riesgos sociales — cesantía, enfermedad y retiro- a través de patrones de solidaridad intra e intergeneracional, la persistencia de los mismos los desbordan en medio de súbitos estallidos de burbujas financieras y de conflictos conexos de diversa naturaleza - geopolíticos, religiosos y ambientales-.

La discusión que prosigue se desarrolla del modo siguiente. En una primera sección, se profundiza el contorno epistémico sobre lo distribucional y las elecciones entre libertad y justicia subyacentes al discurso económico moderno; en la segunda, se reintroduce el fenómeno vaciamiento social de la economía y la emergencia de aproximaciones electivas menos cerradas que abren su horizonte cognitivo. En la parte final, se ofrecen algunas reflexiones que delimitan el alcance de los términos en debate bajo las nuevas condiciones según las que los propios referentes de la modernidad se han vuelto líquidos (Bauman, 2007) o mucho más densos, a su vez.

\section{ELECCIÓN: RACIONALIDAD ECONÓMICA Y MORAL}

En el pensamiento económico moderno, subyace fuera de toda discusión el dominio estricto de la dimensión «libertad» como su constructo discursivo fundamental. Efectivamente, en la tradición liberal «racionalidad económica y eficiencia» aparecen performativas a «elección y comportamiento optimizador»; en su mutua y simultánea relación, por lo tanto, se funda la axiomática constitutiva del mundo de la libertad, y el recurso para su legitimación, si es que éste existiera, queda confinado al crecimiento económico, el que gracias a la fuerza intrínseca del principio 
suma positiva que lo gobierna eclipsa ipso facto lo redistribucional. Esta prescripción cristalizada en el criterio electivo Pareto óptimo inequívocamente evalúa eficiencia e inhibe desigualdad. ${ }^{2}$

El señorío electivo por la dimensión «libertad», asimismo, no resulta completamente diferente en el pensamiento crítico de Marx. La «explotación capitalista» no constituye una tematización de tipo moral, sino una de naturaleza estrictamente económica dado el mecanismo de producción mercantil que ventila «trabajo enajenado» y, por tanto, conculca la «libertad» sobre todo de la clase social subordinada en la cual se funde y amalgama el individuo de forma indisoluble y cuya desalienanción transvasa su impronta individual. En síntesis, desde la discursiva económica moderna, la dimensión equidad pierde su significación imperativa en las manos del liberalismo y aparece como una promesa atada a la misión mesiánica y emancipadora del trabajo en Marx, la cual se encargará de poner fin a la fuente de su negación.

La comprensión, en cambio, de contenidos como los que invoca: «protección social», requiere una perspectiva electiva más vasta, que incluye una de tipo menos cerrada en la escala binaria libertad-justicia según la cual la individuación como fenómeno constitutivo de la modernidad y sobre todo, otra, la praxis de libertad individual no solo implica una arista utilitaria, egoísta, sino que también alberga al sujeto moral capaz de dominarse, de vincularse con los demás, de vivir en sociedad.

Para el tratamiento de la equidad, en consecuencia, el modelo convencional de elección se presenta claramente insuficiente, dado que sus predicciones optimizadoras, basadas en el nivel de utilidad y satisfacción, carecen de sentido cuando no se considera un marco societal más amplio como el que provee, por ejemplo, el planteamiento de «la falta de oportunidades», o, de manera aún más precisa, el de privación de capacidades, sin cuya consideración se soslaya y menoscaba la autonomía y la libertad individual especialmente del decidor en situación de desventaja. Su inclusión, no solo faculta una mejor comprensión de la propia agencia de los individuos en contextos sociales a escala individual cada vez más intensos, sino que repotencia categorías emancipatorias marxistas como la de individualidad-genérica, irónicamente coartada por los «Estados obreros» fallidos, y en una mejor sintonía con paradigmas comprehensivos como el de la complejidad. ${ }^{3}$

En este segundo sentido, Karl Polanyi incursiona en los contornos de lo social -y particularmente en la protección social- al contrastar el vacío que deja su propia denegación en el momento mismo en que se afianza el imperio unívoco de la economía en la sociedad. Aunque en Polanyi predomina aún la contraposición individuo y sociedad desde una lógica de anonimato - la socialización de los individuos-, su interpelación pionera todavía no faculta visualizar a la multiplicidad de sus integrantes como individuos diferentes y singulares.

El producto de la deconstrución del lazo social que se cristaliza en los avatares de la transición y del triunfo hacia el mercado autorregulador, termina, según Polanyi, desintegrando el mundo de lo intraindividual, que hasta ese momento cohabita nítidamente en las lógicas «del sentido de pertenencia» que se yuxtaponen y conviven entre las solidaridades estamentales de las sociedades tradicionales, en cuyo seno el principio del intercambio guiado por el interés propio constituye uno entre muchos más. ${ }^{4}$

En esas sociedades el individuo no está en el centro de la representación de la vida social, porque allí los espacios para la elección están acotados y porque las distintas esferas de la vida 
social están fuertemente entrelazadas; Estado y religión, familia y economía, están poco separadas. En cambio, las sociedades modernas, individualistas abren esos espacios: separan la religión y el Estado, lo público y lo privado, y, sobre todo, consideran que el individuo es una realización moral y una fuente de legitimidad política (Dubet, 2015, p. 65).

Bajo la hegemónica motivación del beneficio e interés propios, empero, el intercambio de bienes no morales erosiona, sin ninguna solución de continuidad, el principio tradicional de pertenencia y su papel de representación en la vida social, apelando para su propia realización de la racionalidad electiva que en esas condiciones resulta simultánea, perfomativa al ejercicio de la libertad y soberanía plenos. Liberado, entonces, del criterio de simetría, el comportamiento y conducta individual deviene utilitario en detrimento y en oposición permanentemente a lo intraindividual; se degrada sucesivamente su condición primigenia e imperativa y se circunscribe progresivamente en sí mismo como esfera subalterna cada vez más autonomizada.

Este señorío electivo de carácter acotado, binario en la escala libertad-justicia, constituye, sumariamente, el lugar común de todas las teorías modernas sobre distribución. Aunque algunas de ellas, las más influyentes, la asocian estrictamente al mundo económico, otras lo hacen en torno a la esfera de la moral. Sin excepción. En el marxismo clásico, la elección por «la emancipación» como ontología autocreadora para la realización futura de la sociedad reconciliada encarna la finitud en sí mismo de la desigualdad. Un predominio epistémico equivalente articula la «optimalidad Pareto» que eclipsa la desigualdad por la supremacía de la capacidad electiva y los efectos «suma positiva» del crecimiento económico. Simplificando, la dinámica subyacente a partir de la cual se operacionalizan los valores que fundamentan opciones distributivas alternativas resultan clave en la medida en que su vigencia modifica los mecanismos institucionales que afectan a lo distribucional tanto en su sentido más convencional - la propiedad y las dotaciones - como en su escala menos acotada de nivelación de capacidades y oportunidades.

Para visualizar los vectores de esa disputa, es necesario referenciar las proposiciones específicas en debate. Uno de los planteamientos centrales de Marx es que la sociedad capitalista, como en toda sociedad donde las relaciones económicas se definen a partir de clases sociales, existe explotación. Esto significa que algunos se benefician de lo que producen otros. En la base del planteamiento, la elección por la emancipación resulta definitiva, ya que ella misma equivale a la negación de la fuente de su mengua, el trabajo enajenado. Los marxistas clásicos, en efecto, responden que la vigencia del trabajo enajenado restringe la libertad. Los partidarios, en cambio, del socialismo de mercado, postulan que es la equidad, o la falta de equidad atada a la explotación, la que termina trabando la construcción de la libertad (Gallardo, 2007, p. 213).

En un campo de debate más amplio se puede advertir que las consecuencias que devienen de este tipo de elección influyen en el momento en que se conciben instrumentos distributivos para el tratamiento de la desigualdad y exclusión, dado que invocan implicaciones diferentes y en conflicto. Si la elección central, por ejemplo, gira en torno a la libertad, se posa en el centro la confrontación y negociación políticas entre los grupos que imprimen el proceso económico. Por el contrario, si el criterio que se defiende es la igualdad, las implicaciones distribucionales son de orden moral con acuerdo político. 
En el primer caso, la libertad y los medios para su realización se apoyan en la expansión de los «bienes no morales»: el espacio de la renta y del crecimiento económico; en el segundo, solo se la alcanza con el aumento de «bienes morales»: el espacio de simetría y de cohesión social. En resumen, en las sociedades actuales, libertad e igualdad, afectan los mecanismos institucionales y las políticas asociadas terminan siendo de naturaleza económica en el primer sentido, donde la finalidad de la confrontación se atiene a la lucha por el excedente económico, $y$, en el otro caso, son de orden moral lo que circunscribe el conflicto en aquello que se debe igualar y a qué nivel (Gallardo, 2007, p. 214).

\section{EL VACIAMIENTO SOCIAL DE LA ECONOMÍA MODERNA}

La transición hacia los mercados autorregulados, según Polanyi, implica una profunda transformación según la cual se invierte la lógica de las sociedades humanas: en lugar de que la economía se vea marcada por las relaciones sociales, son las relaciones sociales las que terminan encasilladas en el interior del sistema económico. Sumariamente, con esta subordinación de lo social, la economía de mercado únicamente puede funcionar como sociedad de mercado que, por lo demás, y como mecanismo asignativo, resulta mucho menos el producto de un orden natural y mucho más de opciones electivas deliberadas. ${ }^{5}$

Ese conjunto progresivo de elecciones menos abiertas en la escala libertad-justicia coartan la simetría como principio de interacción y relacionamiento humano: optar más por la una implica, evidentemente, el menoscabo de la otra. En la medida en que la motivación basada en el interés propio deviene hegemónica, simultáneamente se debilita y desmorona la cohesión que articula lo intraindividual; la extensión compulsiva del comportamiento utilitario, en definitiva, acota y circunscribe lo social al menguar la simetría y reciprocidad como criterio constitutivo para la interacción y el reconocimiento subjetivo de los individuos. La masa es lo que queda cuando se hace desaparecer lo social.

La legitimidad del vaciamiento social en la sociedad moderna, y particularmente la que emerge desde sus formas de individuación utilitarias, hecha raíces en la expansión sin precedentes de las mejoras materiales que experimenta la economía, cuyos beneficios, en su balance de cuentas, superan a los costes incurridos por la desintegración de lo social y su fenomenología trivial: el desamparo, el desempleo y subempleo, el daño ambiental.

La continua proscripción de lo intraindividual implica, en realidad, una transformación profunda del tejido social. En cierto sentido, no es tanto en el intercambio de los bienes no morales - de los bienes privados - donde se afincan los trastornos sustantivos del lazo social, sino fundamentalmente en el ámbito y espacio de los bienes morales. Si bien la producción de los primeros requiere la mercantilización de la naturaleza y del individuo mismo, el proceso de representación política, en cambio, empodera potencialmente la subjetividad individual al transformarla en fuente de su legitimación. Esta metamorfosis profunda y de doble vía, consiguientemente, modifica críticamente el significado del intercambio de bienes morales para el relacionamiento individual y de reconocimiento intersubjetivo.

La consecuencia de un proceso electivo acotado que transforma ese dispositivo en disputa se convierte en una fuente desbordada que desemboca en desarraigos sociales y ambientales. 
La pérdida de simetría y reciprocidad, tanto en la esfera económica como en la representación política, hace colisionar lo intraindividual sobre sí mismo. En gran parte, la propia expansión geométrica del intercambio de bienes no morales que resulta simultánea a las mejoras fácticas debilitan las opciones de resistencia y determinan que el costo social incurrido resulte menor comparado con los beneficios, cada vez más hedónicos, que ofrecen esas mejoras materiales. ${ }^{6}$

Esa capacidad desbordada y expansiva del intercambio de los bienes no morales resulta incluso subestimada por la teoría de la explotación que, en su momento, formula una coherente narrativa para explicar el origen de la opulencia capitalista a partir de la desposesión y pauperización creciente de la clase social explotada, soslayando, sin embargo, el hecho de que los salarios llegaren a ser más elevados en los tugurios industriales que en el resto de sectores económicos y que, en su conjunto, continuasen aumentando de forma más o menos sostenida. ${ }^{7}$

El capital de Marx, efectivamente, no logra advertir esa situación subrepticia, documentada ciento cincuenta años más adelante, entre otros, por El capital en el siglo xxi de Piketty, ${ }^{8}$ según el cual no fue sino hasta el último tercio del siglo xix cuando ocurrió un incremento significativo del poder adquisitivo de los salarios luego evidentemente de un periodo de prosperidad excluyente del capital y de los beneficios industriales.

Sumariamente, si bien el crecimiento económico moderno y la difusión de los conocimientos que éste patrocina, han permitido evitar el derrumbe capitalista, anticipado prematuramente por Marx, tampoco sus lógicas logran modificar las estructuras profundas del capital y de las desigualdades, o, por lo menos, no tanto como se imaginó, por ejemplo, en las décadas optimistas posteriores a la Segunda Guerra Mundial.

$\mathrm{Ni}$ el crecimiento económico ni las nuevas técnicas y tecnologías, ostentan, en consecuencia, la capacidad de limitar la inestabilidad económica que se sustentada en la inequidad; por el contrario, la emergencia de fluctuaciones recurrentes exponen, según sus diferentes niveles de profundidad, a la sociedad y la naturaleza. Una gran parte de la explicación de esa inestabilidad sistémica y de sus fuentes intrínsecas se origina en la violación creciente del criterio de simetría. Cuando los retornos del capital, en efecto, superan significativamente la tasa de crecimiento en la largo plazo - o cuando en el corto plazo la tasa nominal supera a la tasa natural de interés, la eficacia marginal de capital, en la semántica keynesiana- la riqueza originada en el pasado se recapitaliza más rápido que el ritmo de crecimiento de la producción, de la inversión y de los ingresos.

Basta, pues, que los «herederos» ahorren una parte limitada de los ingresos de su capital, para que este último aumente más rápido que el conjunto de la economía - y se puede documentar que este desacople ha sucedido siempre en la historia, por lo menos hasta el siglo XIX, y que existe evidencia de que puede ser la norma en el siglo xxI-. En estas condiciones, es casi inevitable que los patrimonios heredados dominen por mucho a los patrimonios constituidos a lo largo de una vida de trabajo y que la concentración de capital alcance niveles muy elevados y potencialmente incompatibles con los valores morales y los principios de justicia que sustentan la cohesión social de las sociedades democráticas (Piketty, 2014).

Esta argumentación más amplia replantea el contexto cognitivo de la teoría económica convencional modificando la naturaleza electiva de tipo cerrada, binaria en la escala libertad/justicia bajo cuyas proposiciones se acotan y eclipsan la simetría a favor de desigualdad y 
exclusión. Al delimitarse casi compulsivamente el campo y objeto de estudio alrededor y predominio de una individuación persistentemente unidimensional, compatible con entornos de vaciamiento social de la economía, las teorías del bienestar y del crecimiento balanceado, en consecuencia, subestiman la falta de simetría y la fragmentación del lazo social que se subsumen en sí mismos.

Con un tipo de elección más abierta, en cambio, Sen muestra los límites de la teoría del bienestar basada en la métrica utilitarista sin menoscabar la capacidad electiva individual en la que también caben empatía y sentimientos morales. La ventaja de esta lente epistémica que emerge desde «la denegación de oportunidades» transvasa el espacio de las «utilidades» no solo porque la base de información requerida es más amplia, sino porque contextualiza las connotaciones acotadas con las que se evaluaba el bienestar. El espacio menos restrictivo sobre las «capacidades para funcionar» brinda una historia más comprehensiva sobre el bienestar individual que incluye un rol constitutivo en sí mismo de lo social al relativizar su consuetudinario papel instrumental. ${ }^{9}$

El horizonte de análisis más abierto que propone Piketty, por su parte, contribuye a evidenciar las limitadas implicaciones que arroja la teoría del crecimiento balanceado en el cual el retorno de capital inequívocamente converge hacia la tasa de crecimiento. Este resultado, sin duda parcial, no puede defenderse cuando se utiliza una base de información mucho más amplia; dentro de ese marco más vasto, de igual manera, se puede evidenciar la falta de sustento empírico alrededor del principio de acumulación infinita y de divergencia perpetua expresado por Marx, desde cuya base se predice el desenlace apocalíptico del capital cuando se asume intuitivamente, sin mayor evidencia, un incremento rigurosamente nulo de la productividad a largo plazo (Piketty, 2014).

Sumariamente, estas formas remozadas de fundamentación teórica que apelan a bases de información más amplias facultan elecciones mucho más abiertas que disipan soluciones restrictivas de tipo binario y en mucho mejor sintonía con fronteras cognitivas como las que traza el pensamiento complejo en las que al reconocerse las connotaciones propias de las construcciones teóricas somete al mismo tiempo los niveles de pertinencia a la complejidad problémica donde adquieren sentido las diferentes de bases de información y las métricas subsecuentes. ${ }^{10}$

\section{INDIVIDUACIÓN UNIDIMENSIONAL E INDIVIDUACION GENÉRICA}

Entre el amplio género de desigualdades y asimetrías, las de naturaleza económica son con seguridad las más influyentes. Su incidencia y protagonismo no solo están presentes en las explicaciones macro y funcionales sobre la falta de estabilidad del sistema económico, sino que los resultados de los experimentos que en la actualidad la economía del comportamiento documenta, develan su importante papel causal cuando detectan que la ausencia de equidad dentro del canon y contornos de la racionalidad instrumental producen animals spirits que en la narrativa keynesiana desencadenan la inestabilidad sistémica y recurrente del capitalismo. ${ }^{11}$

La estrecha y observable asociación entre desigualdad e inestabilidad, por tanto, se encuentra fuera de toda duda. Efectivamente, esa relación emerge con mucha claridad cuando se consideran horizontes temporales más amplios. La última vez que la desigualdad se aproxima a 
la actual cota extrema remite a la de los años previos a la Gran Depresión. Exceptuando el periodo entre 1950 y 1970, en el que se reduce la desigualdad, los últimos ciento cincuenta años constituyen un periodo donde se afianzan simultáneamente una fuerte concentración de riqueza y el estallido de las dos recesiones más profundas y prolongadas registradas en la historia del capitalismo.

Esa fase de expansión económica, observada desde la segunda posguerra se explica, en parte, por el desarrollo de los mercados, pero mucho más por las políticas inclusivas, como la mejora del acceso a la educación superior y la vigencia de un sistema tributario progresivo. El retorno al credo del mercado autorregulador en los años posteriores desencadena un aumento de la divisoria entre los ingresos personales y el desmantelamiento de las iniciativas diseñadas para mitigar los excesos del mercado, como la reducción de los impuestos a la rentas altas y el recorte de los programas sociales (Stiglitz, 2014, p. 51).

Las fuerzas de mercado desempeñan por sí mismas un papel adverso sobre el alcance de la desigualdad económica, pero esas mismas fuerzas entran también en juego en otros países de industrialización avanzada, donde el intercambio de bienes morales, en cambio, genera otros resultados de naturaleza diferente. En unos casos, ese intercambio se expresa en el reconocimiento de lo que constituye lo socialmente aceptable entre el ámbito de la responsabilidad individual y el que corresponde al de la responsabilidad social. ${ }^{22}$

En aquellos contextos en que la ética sobre la responsabilidad social se acota y el mecanismo de mercado refuerza su tendencia compulsiva hacia la concentración, la dinámica especifica que sigue el intercambio de bienes no morales genera un vacío de protección social. Durante los últimos treinta años, en efecto, Estados Unidos se ha convertido cada vez más en una nación dividida, mucho más diferenciada; quienes se ubican en la parte alta de la distribución, según Stiglitz, no solo crecen más de prisa, sino que de hecho empeoran aquellos que se afincan en la parte inferior.

En el periodo más reciente de gran inestabilidad económica se hacen más visibles el vaciamiento social y la explosión de los desarraigos laborales; quienes tienen empleo intuyen que sus ocupaciones y trabajos se encuentran en peligro y que con el elevado nivel de desempleo y la escasa protección social, sus vidas podrían dar un repentino giro hacia una cada vez más precaria situación. La pérdida de empleo significaría quedarse sin cobertura de seguro médico e incluso de afrontar la pérdida de su residencia; quienes tienen un trabajo aparentemente seguro se enfrentan a una jubilación incierta debido al riesgo de las fluctuaciones de la bolsa que arbitran los fondos previsionales.

La actual expansión de la desigualdad y la forma en que ella se genera, en realidad, rebasa el ámbito del intercambio de bienes morales — la falta de protección y responsabilidad socialy socava el crecimiento económico sustentado en la extensión de la productividad y eficiencia. Una parte muy importante de la desigualdad contemporánea es consecuencia de las distorsiones en la propia acumulación de capital, ralentizada por el desastre ambiental, y en cuyas manifestaciones se plasman en la orientación que adopta el mecanismo de mercado con unos incentivos dirigidos no a crear nueva riqueza, sino arrebatársela a los demás (Stiglitz, 2014, p. 52).

Ese nivel implosivo del sistema económico reposiciona lo distribucional —dado que el vínculo inestabilidad y desigualdad tiende a expresarse más a través de una lógica distribucional 
suma cero: el bienestar de una clase social es fruto de la creciente desventura de la clase desposeída- y actualiza la tesis emancipatoria en un contexto diferente. En una sociedad en la que el futuro ya ocurrió y, en consecuencia, se tiene presente que la alienación no desaparece en entornos con medios de producción colectivizados, ${ }^{13} \mathrm{y}$ en la que persiste con más radicalidad la polaridad libertad-justicia como disyuntiva acotada al paradigma de simplicidad, los desafíos cognitivos y posibilidades para su realización forman parte, cada vez más, del mundo de la complejidad. ${ }^{14}$

Uno de sus vectores, la construcción de la «libertad objetiva», fundamental para la negación de la «alienación», resulta cuarteado por el desastre ecológico que agrieta los cimientos de la misión mesiánica de las fuerzas productivas y pone en duda la total eliminación de la escasez. Un orden social diferente requiere, por tanto, de mecanismos institucionales que hagan posible la distribución con criterios de justicia. La fuerte diferenciación y la explosión de las subjetividades que se transforman en una amplia y diversa gama con infinidad de manifestaciones entre las cuales unas resultan seguramente más costosas que las otras, resignifican lo redistribucional en medio de ecosistemas que vuelven menos creíble la eliminación de la escasez.

El criterio de equidad necesario para enfrentar el problema técnico de satisfacer las necesidades implica la constatación de que no existe libertad total en un mundo de recursos naturales escasos, pero que se puede lograr un nivel tolerable complementándola con criterios de justicia. ${ }^{15}$

El signo mayor para afianzar las posibilidades emancipatorias residiría más en los individuos mismos, desde cuyas subjetividades la autoconstrucción social se procesaría como resultado de la recuperación de sus capacidades como sujetos deliberantes y a tono con la construcción de las individualidades propias. Si la sociedad capitalista es negativa porque se funda sobre el trabajo enajenante, sigue aun siéndola porque encarna en sí misma la posibilidad de su negación al facultar la constitución del sujeto y de su individualidad genérica.

La realización emancipatoria que niega la alienación siempre se la entendió como un salto estrictamente subjetivo - la explotación capitalista vehiculiza el tránsito hacia la conciencia para sí- y su falta de concreción se volvió problémica en una modernidad cada vez más líquida que progresivamente ha venido reduciendo a esa misma condición al sujeto de la transformación, siguiendo, empero, un itinerario inverso al que teorizó Marx. La conciencia en sí, en lugar de descender desde el espacio del «macrocomportamiento» en donde residía la misión «de clase» redentora hacia la micromotivación individual se trastoca y la actual desconstitución del sujeto viene operando desde el microcosmos, en donde el individuo explotado se convierte en un agente autoexplotado que asimila hacia sí mismo la agresión del capital. ${ }^{16}$

El motor de resistencia frente a esa agresividad ligada a las amenazas de las fuerzas económicas y de los poderes autoritarios que transforman al individuo explotado no en un individuo revolucionario, sino en agente depresivo, obediente y menos deliberante, resignifican la resistencia cuando el proceso de subjetivación actúa en nombre de sus derechos y de su identidad, y las posibilidades de realización del sujeto individual enfrentan precisamente los entornos que tienden a desarticular la convivencia en sociedad, engendran violencia y hacen estallar asimetrías y exclusiones no solo económicas, sino también políticas. 


\section{CONCLUSIÓN}

El planteamiento central de este trabajo es que desde el pensamiento moderno y particularmente desde la teoría económica, no es posible un estudio comprehensivo de la equidad debido al peso de la impronta electiva de naturaleza cerrada entre libertad/justicia que la caracteriza, según la cual o bien el proceso económico la diluye en la lógica del crecimiento económico que en sí mismo presupone una racionalidad suma positiva con efectos distribucionales subalternos, o desde aquélla de implicaciones distributivas suma cero dentro de la cual, en cambio, lo auténticamente justo se difumina indefinidamente mientras perdura la fuente para su negación.

Una nueva perspectiva cognitiva emerge desde el espacio de una individuación menos unidimensional y las bases para su positivización se erigen contrastando los roles electivos cruciales que la distinguen entre las sociedades tradicionales y modernas. El individuo, en las primeras, no se encuentra en el centro de la representación de la vida social porque allí los espacios para la elección están acotados y porque las distintas esferas de la vida social están fuertemente entrelazadas; en las segundas, en cambio, que abren esos espacios crean condiciones para su afirmación cuando no se restringe su realización a la elección utilitaria y se extiende la condición moral que potencia al individuo como sujeto deliberante y nivelador por ser la fuente de legitimidad política.

Estas renovadas incursiones no solo interpelan el modelo de sujeto asimilado a la sociedad apelando a uno que se centra en la subjetividad e intimidad de los individuos, cuyo relacionamiento e interacción se toma como autoconstrucción social la cual permite resignificar el contenido deliberante del lazo y cohesión social.

Esta visión requiere deconstruir elecciones cerradas revalorizando una escala electiva más amplia. Cuando ya no se puede definir un principio común del bien por medio de la religión o de las utopías políticas, el reconocimiento de la singularidad y de la autonomía moral de los individuos se vuelve un «humanismo» $\mathrm{y}$ un ideal que se debe promover al cuestionar acerca de las condiciones de la construcción del individuo y de la comprensión de como ellos se constituyen como individuos menos unidimensionales justamente en el momento en que mengua la incidencia de los polos aparentemente antitéticos: de concentración económica asimétrica y de instituciones autoritarias de disciplinamiento y control (Dubet, 2015).

\section{NOTAS}

1 Polanyi tiene la ventaja respecto a Weber y Durkheim porque atestigua las aleccionadoras experiencias de inicios del siglo xx - el socialismo, la Gran Depresión, el fascismo, el New Deal-como eventos de "autoprotección» que irrumpen en la sociedad de mercado para mantener la integración social (Iazetta, 2008).

2 Para contrastar la axiológica Pareto, autores como Thomas Piketty proponen documentadamente que la expansión de la desigualdad se magnifica en períodos de bajo crecimiento económico.

3 «[...] Los principios del pensamiento complejo, [...] serán necesariamente los principios de distinción, conjunción e implicación. [...] Vamos a reunir lo Uno y lo Múltiple, los uniremos, pero lo Uno no se disolverá en lo múltiple y lo Múltiple será, asimismo, parte de lo Uno». (Morín, 2011, p. 110)

4 La economía experimental avala la pluralidad de motivaciones en el campo electivo. «Prepararon una nueva versión de un juego que normalmente se practica en los laboratorios experimentales y está destinado a analizar la capacidad de cooperación de las personas y la confianza mutua. En la versión 
básica de este experimento, las personas tienen la opción de echar dinero dentro de un «bote» que irá aumentando y luego se repartirá entre el resto del grupo. Si actúan en colaboración, las cantidades que obtienen son mayores. Pero al mismo tiempo existe un aliciente para que alguien actúe con egoísmo, de modo que conseguirá mayores beneficios si los demás ponen dinero en el bote para que aumente y se reparta, mientras ese alguien actúe con egoísmo». (Akerlof y Shiller, 2009, p. 48)

5 Existe una línea muy delgada entre la proposición de Polanyi sobre la naturaleza artificial, creada de los mercados autorregulados (Polanyi, 2008), y la tesis de Acemoglu y Robinson cuando demuestran que los mismos y sobretodo las instituciones que lo hacen posible constituyen variables endógenas y eso significa en la semántica de los experimentos naturales, diseñados para extraer conclusiones causales, que los procesos políticos, incluyendo la distribución del poder, constituyen en cada una de las sociedades, una materia estrictamente electiva (Acemoglu y Robinson, 2012).

6 «El producto bruto de todo el mundo, que se ubica hoy en el orden de los treinta billones de dólares, se multiplicó por tres en los últimos treinta años, y por nueve en el último medio siglo. Gracias al fenomenal incremento de productividad en todos los sectores de actividad, el mundo está hoy en condiciones de alimentar, vestir, alojar y educar dignamente a sus seis mil millones de habitantes e incluso ocho o diez mil millones que la transición demográfica actual permite proyectar para el próximo medio siglo». (Ferullo, 2006, p. 73)

7 «En la época de Ricardo, los salarios semanales de los jornaleros ingleses eran, con frecuencia, inferiores al precio de medio bushel de buen trigo. El salario semanal de los obreros no calificados en Estados Unidos era, por entonces, el equivalente a dos busheles de trigo, y en 1890 cuando se publicaron los Principles de Marshall, se había elevado hasta aproximadamente nueve busheles. Para 1970, la compensación semanal de los obreros de la producción fabril era suficiente para comprar 96 busheles de trigo de alta calidad». (Ferullo, 2006, p. 73)

8 «Al igual que los autores anteriores, Marx pasó totalmente por alto la posibilidad de un progreso técnico duradero y de un crecimiento continuo de la productividad, una fuerza que, como veremos, permite equilibrar - en cierta medida - el proceso de acumulación y de creciente concentración del capital privado. Sin duda, carecía de datos estadísticos para precisar sus predicciones. Sin duda, también fue víctima del hecho de haber fijado sus conclusiones desde 1848, aun antes de iniciar las investigaciones que podrían justificarlas». (Piketty, 2014, pp. 23-24).

9 «De hecho, hemos demostrado en otra parte que considerando algunas caracterizaciones razonables de las libertades individuales fundamentales, una importante parte del resultado sobre la eficiencia de Arrow-Debreu se traslada fácilmente del "espacio" de las utilidades al de las libertades individuales, tanto en lo que se refiere a la libertad para elegir las cestas de bienes como en lo que refiere a las capacidades para funcionar. Para demostrar la viabilidad de esta extensión se emplean supuestos parecidos a los que se necesitan para obtener los resultados obtenidos por Arrow-Debreu - como la ausencia de bienes que no se pueden vender-. Con estas presuposiciones, resulta que, considerando una caracterización convincente de las libertades individuales, un equilibrio de mercado competitivo garantiza que no es posible aumentar la libertad de una persona y mantener al mismo tiempo la libertad de los demás». (Sen, 2000, p. 149)

10 «Finalmente la complejidad científica es la presencia de lo no científico en lo científico que no anula a lo científico, sino que, por el contrario, le permite expresarse. Creo que, efectivamente, la ciencia moderna, a pesar de las teorías simplificadoras, es una empresa muy compleja». (Morin, 2011, pp. 147-148) 11 «Por tanto, para comprender la economía conviene entender de qué modo se ve afectada por estos espíritus animales. Al igual que la mano invisible de Adam Smith representa la idea central de la economía clásica, los espíritus animales de Keynes constituyen la clave de otra visión diferente de la economía, una perspectiva que explica las inestabilidades que subyacen en el capitalismo» (Akerlof, 2009, p. 10). 12 «Tras estas diferencias y las respectivas prioridades de las políticas económica y social relacionadas con ellas, puede existir un importante contraste entre las actitudes de los dos lados del Atlántico hacia las responsabilidades sociales e individuales. En las prioridades oficiales de Estados Unidos, apenas existe el compromiso de protección por asistencia médica básica a todos; como resultado, muchos mi- 
llones de personas carecen de cobertura o seguro médico. En cambio, en Europa donde se considera que la protección médica es un derecho básico, independientemente de los medios y de las enfermedades que padezcan los individuos, en principio, resultaría inaceptable políticamente una situación parecida. En contraste, las tasas de paro de dos dígitos que se toleran actualmente en Europa serían con toda probabilidad dinamita política en Estados Unidos, ya que unas tasas de paro de esa magnitud serían una burla para la capacidad de los individuos de ayudarse a sí mismos; esas diferencias no solo reflejan divergencias en los respectivos compromisos éticos». (Sen, 2000, p. 127)

13 El planteamiento de que la enajenación del trabajo desaparece en el momento en que la producción queda nacionalizada es difícil de defender; al parecer, emerge otra enajenación que supone el trabajo fatigoso y absorbente por muy racionalizado que esté. Violenta al Hombre toda realización social que no tenga en cuenta que solo la riqueza verdadera la proporciona, el tiempo libre, que se convierte en la medida de riqueza. Utilizar el tiempo de trabajo como medida de la riqueza es basar esta misma riqueza sobre la pobreza. (Castellet, 1971)

14 «La simplicidad ve a lo uno y a lo múltiple, pero no puede ver que lo Uno puede, al mismo tiempo, ser Múltiple. El principio de simplicidad o bien separa lo que está ligado (disyunción) o bien unifica lo que es diverso (reducción)». (Morín, 2011, p. 89)

15 Esto no refuta la noción de Marx, sino que otorga sentido a la elección moral, no ya como algo accesorio al criterio emancipador, sino como sostén de la estructura social (Gallardo, 2007, p. 236).

16 «Quien fracasa en la sociedad neoliberal del rendimiento, se hace a sí mismo responsable y se avergüenza en lugar de poner en duda a la sociedad o al sistema. En esto consiste la especial inteligencia del régimen neoliberal. No deja que surja resistencia alguna contra el sistema. En el régimen de explotación ajena, por el contrario, es posible que los explotados se solidaricen y juntos se alcen contra el explotador. Precisamente en esta lógica se basa la idea de Marx de la "dictadura del proletariado". Sin embargo, esta lógica presupone relaciones de dominación represivas. En el régimen neoliberal de la autoexplotación, uno dirige la agresión hacia sí mismo. Esta autoagresividad no convierte al explotado en revolucionario, sino en depresivo». (Han, 2014, p. 10)

\section{REFERENCIAS}

Acemoglu, D. y Robinson, J. (2012). ¿Por qué fracasan los países? Bogotá, Colombia: Deusto.

Akerlof, G. y Shiller, R. (2009). Animal spirits. Barcelona, España: Gestión 2000.

Bauman Z. (2007). Vida de consumo. México DF, México: FCE.

Bernstein, R. (1994). Habermas y la modernidad. Madrid, España: Ediciones Cátedra.

Dubet, F. (2015). ¿Para qué sirve realmente un sociólogo? Buenos Aires, Argentina: Siglo XxI.

Castellet, J. M. (1971). Lectura de Marcuse. Barcelona, España: Editorial Seix Barral.

Ferullo, H. (2006). Luces y sombras del pensamiento económico moderno. Buenos Aires, Argentina: UNT.

Gallardo, Á. (2007). Políticas distributivas, marxismo de elección racional y marxismo clásico: Un análisis comparativo. REI, 9(17), (s. p.).

Han, B. C. (2014). Psicopolítica. Barcelona, España: Herder Editorial.

Iazetta, O. (2009). Libertad y regulación en una sociedad de mercado: los parecidos de familia en Durkheim y Polanyi. Buenos Aires, Argentina: Scielo.

Morín, E. (2011). Introducción al pensamiento complejo. Madrid, España: Gedisa.

Piketty, T. (2014). Capital in the twenty-first century. Cambridge, usa: Harvard University Press.

Polanyi K. (2008). La gran transformación. Madrid, España: Quipu Editorial.

Sen, A. (200o). Desarrollo y libertad. Buenos Aires, Argentina: Planeta.

Stiglitz, J. (2014). El precio de la desigualdad. Barcelona, España: Black Print CPI. 